\title{
MEASURING BRIDGE FLEXURAL STRENGTH USING CONTROLLED TRAFFIC DYNAMIC TEST
}

\author{
Ahmed S. Hashad \\ Construction Research Institute, National Water Research Center, Egypt.
}

\begin{abstract}
A steel bridge was subjected to loads which are over its capacity load. Strengthening works were done to allow passing of the required load. To ensure that the strengthened works gained enough increase in flexure stiffness, a dynamic test using controlled traffic technique was performed. The bridge dynamic characteristics before and after strengthening work and just after passing of load were determined. Experimental studies were carried out on two spans for a multiple simple spans bridge using a certain vehicle passing over the bridge. The bridge acceleration response was measured and the bridge fundamental frequency was determined for each span before and after strengthening and after passing of load. The results were used to evaluate the bridge flexure stiffness.

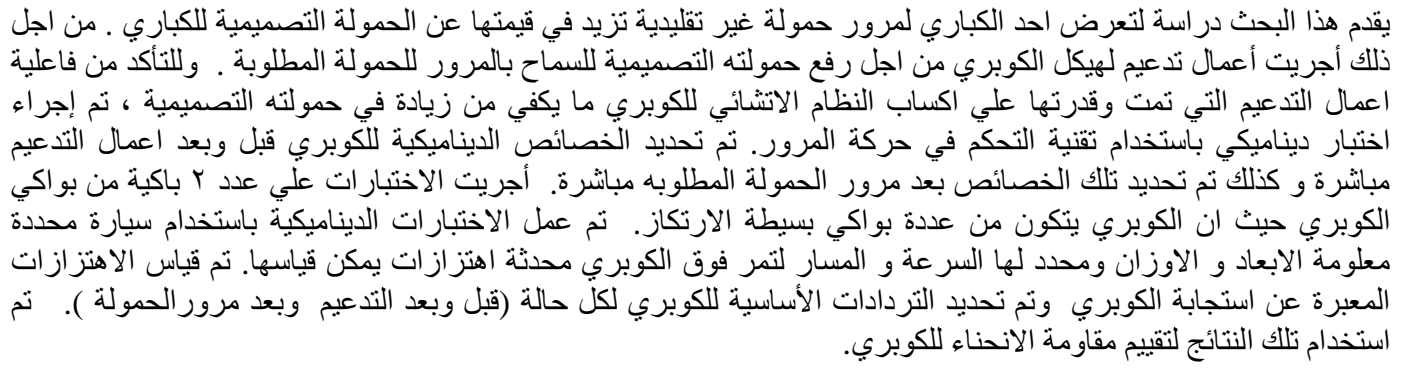

Keywords: Dynamic Testing, Bridges, Impact Factor, Dynamic Response, Strengthening Evaluation

\section{INTRODUCTION}

This study was done upon the request of one of the transportation companies working in transportations of special and nontraditional cargos. The company had a transportation project to transport a very heavy load which is considered over design load for one of the bridges lying in its path. This bridge was strengthened to increase its load capacity. The aim of this study is to examine the dynamic behavior of bridge and to ensure that the bridge strengthening work is efficient by comparing its new flexural stiffness with the original one. If the results show that the flexural stiffness reaches the required flexural stiffness, the special load will be allowed to pass. The testing work was divided into three stages. The first stage was done before any strengthening work. The second stage was performed after all strengthening works have done. The last stage was performed after special load passing. Figure 1 shows the special load when passing over the bridge.
Many researches were done to study or use the relation between bridge dynamic characteristics and bridge global stiffness as in [4], [5], [6] and [7] .

A previous study [3] was carried out on reinforcement concrete bridge with one span frame type structural system. The repair work was carried out because of existence of some deteriorations problem using injection techniques to fix cracks. The bridge global stiffness was estimated using modal testing method.

In this study the bridge is a multiple simple spans bridge with steel main girders. The bridge slab is concrete deck acting with the steel main girders by composite action.

The bridge has no structure problems but it was required to increase its load capacity to allow passing of the special load. The bridge global flexural stiffness was increased by increasing the main girder cross sections. The main girder lower flange cross section was increased by adding extra two plates welded to the original flange, the extra plates with 12 mm thickness each. 
The added plates have width which is smaller than the original flange plate width to allow welding process. Figure 2 shows the added plates.

The calculated inertia for the intermediate main girder about its major axis is $0.0146 \mathrm{~m}^{4}$ before strengthening and $0.0188 \mathrm{~m}^{4}$ after strengthening. The strengthening works increase the global flexural stiffness by $29 \%$. The bridge was designed according to the Egyptian code for loadings for roadway bridges to sustain the standard vehicle load (60 ton + 30 ton). The special load was carried on a vehicle with axle load exceed the design axle load with $10 \%$ without calculating the impact effect.

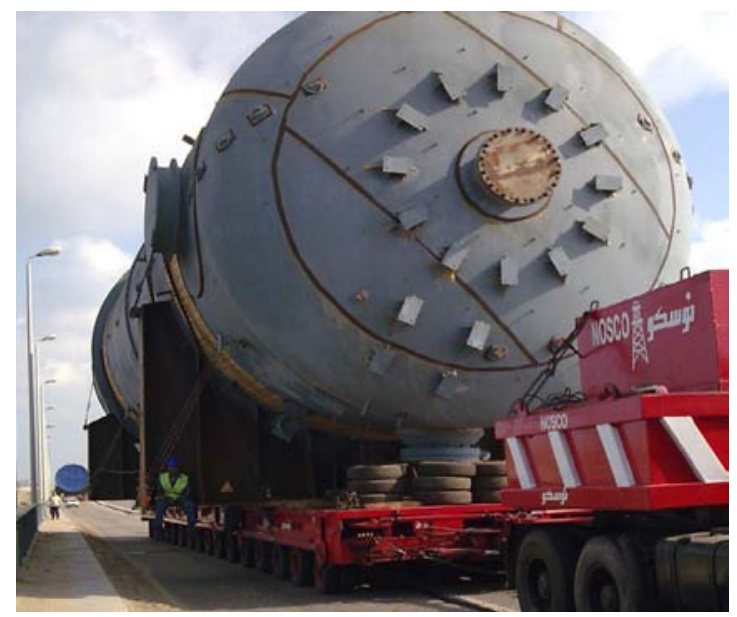

Fig.1 Special Load Passing Over the Tested Bridge

A simple dynamic test using controlled traffic excited method was used to determine the change in the bridge flexural stiffness due to strengthening works, depending on the effect of flexural stiffness on the value of dynamic bending modes frequencies.

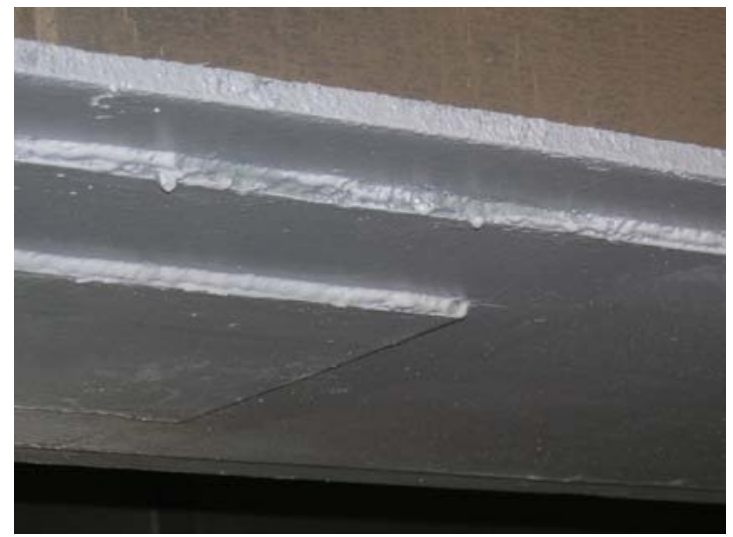

Fig. 2 Adding Plates Welded to Lower Flange of the Tested Bridge

\section{BRIDGE DESCRIPTION}

The bridge consists of eight steel plate girders as simply supported beams type. The deck of the bridge is reinforced concrete slab rested on main girders using shear dowels to gain composite action. Four rigid cross girders at spacing which doesn't exceed $5.50 \mathrm{~m}$ were used. The bridge is called Ashtom ElGammed No.2 Bridge. This bridge consists of 13 spans crossing water pass way (El-Manzala Lake). Figure 3 shows a general view for the bridge.

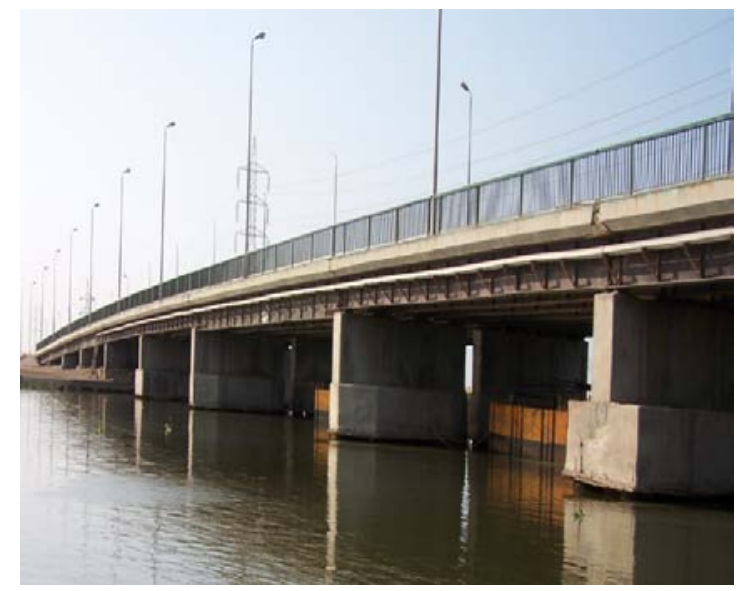

Fig. 3 General View for the Tested Bridge

The intermediate span is $30 \mathrm{~m}$ while the other spans are equal spans with $22.0 \mathrm{~m}$. The supporting system consists of piers over pile cap supported on piled foundation. The bridge deck main system is shown in Fig. 4.

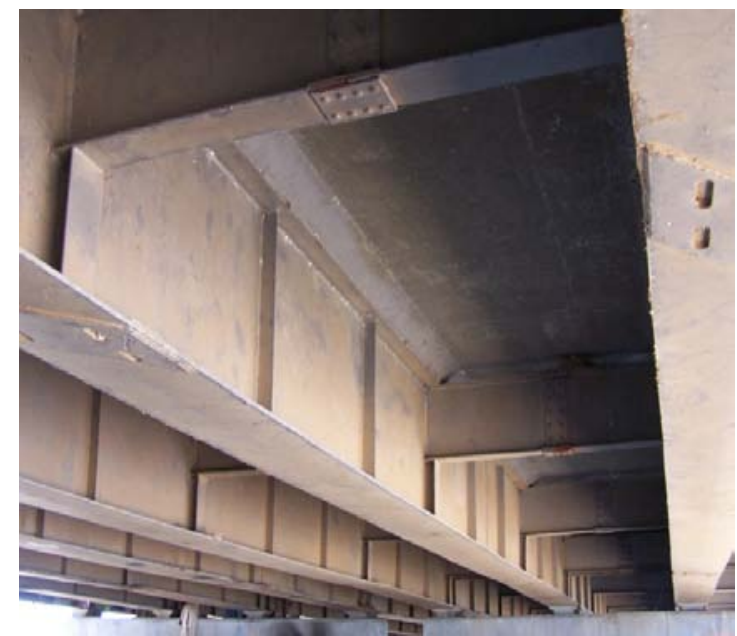

Fig. 4 Bridge Main System 


\section{METHODOLOGY}

The dynamic behavior of the bridge was evaluated by measuring the fundamental frequency of the bridge. Eight accelerometers were attached to the main girders to record the acceleration response induced from the controlled traffic. The accelerometers send the measured signals to data acquisition through connecting cables. The card controls the measuring process and converts analog signals to digital ones. The acquisition card passes the digital data to a laptop computer for the purpose of data storage and analysis. The data is filtered and the basic frequencies are determined. The sequences of the data acquisition are shown in Fig. 5.

The used accelerometers were ICP, Model No. 393A03 having a resonant frequency of more than 10 $\mathrm{kHz}$. Line powered signal conditioners were provided to supply constant current excitation to piezoelectric sensors. The type of the data acquisition cards is PCD-320A. Software produced by KYOWA was used to control the measurements from all channels. The software "ME' scope Visual Modal” is used to filter and analyze the recorded data and consequently to determine the dynamic behavior of the structures.

Modal analysis was used to characterize resonant vibration in structures. By using the ME' scope Visual Modal one can identify the frequency, damping and mode shapes.

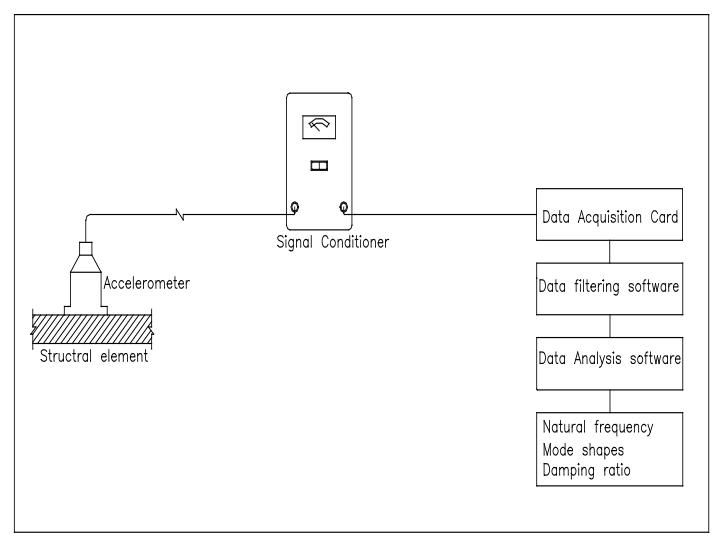

Fig. 5 Data Acquisition System Configuration

\section{TEST SETUP}

Eight accelerometers were mounted to the bottom flange of the two external main girders of the steel bridge. They were distributed all over the span of the bridge, four accelerometers at each main girder. Figure 6 shows the positions of these accelerometers and Fig. 7 shows a photo of one of the installed accelerometers.

The vibration of the bridge is recorded with the rate and time length as shown in table (1).

Ten records are collected to achieve an acceptable accuracy.

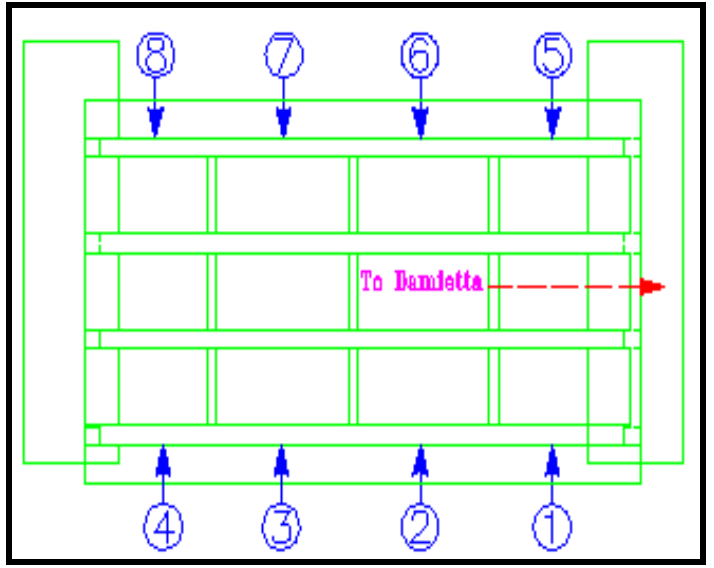

Fig. 6 Accelerometers positions

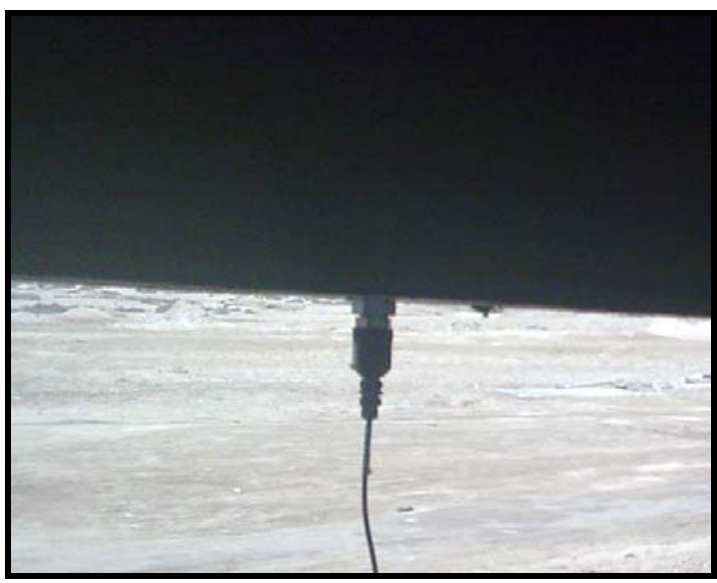

Fig. 7 Photo of one of the installed accelerometers

Only five records were selected for further analysis. The dynamic test was carried out using the induced vibration due to passing of specific vehicle. The vehicle shape and specifications used to excite the bridge is shown in Figs. 8 and 9.

The testing work is done only on the part of the bridge where the traffic is directed to Damietta where the load path.

Table 1, Test Characteristics

\begin{tabular}{|l|l|}
\hline Sampling Rate & 200 sample / sec \\
\hline Number of records & 5 \\
\hline Recorded Time & $25 \mathrm{Sec}$ \\
\hline Cut off Frequency & $25 \mathrm{~Hz}$ \\
\hline
\end{tabular}

The signal processing techniques applied on time record of the bridge acceleration response to determine the bridge fundamental frequency. These techniques such as Cut-off frequency taking into account the Nyquist frequency, the choice of the type of filter to be used to remove noises making the signal-to-noise ratio acceptable [8]. 


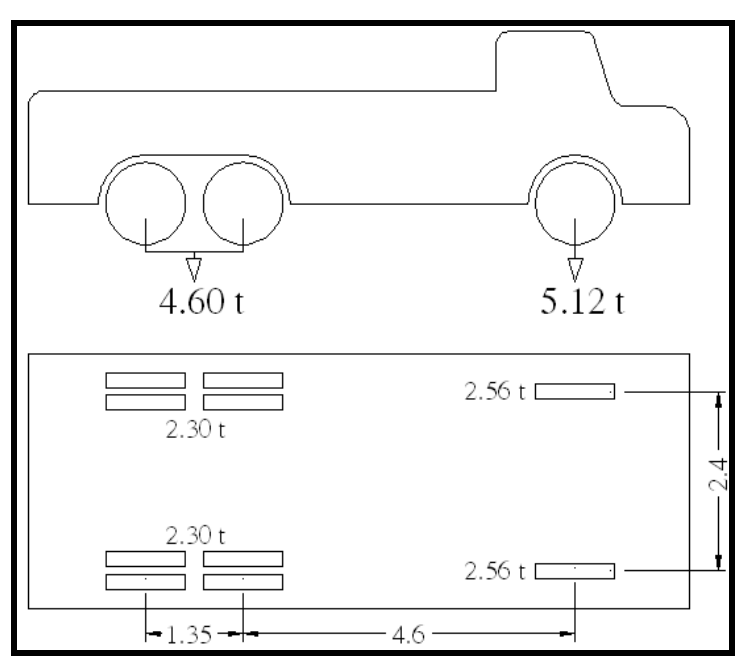

Fig. 8 Vehicle Configuration

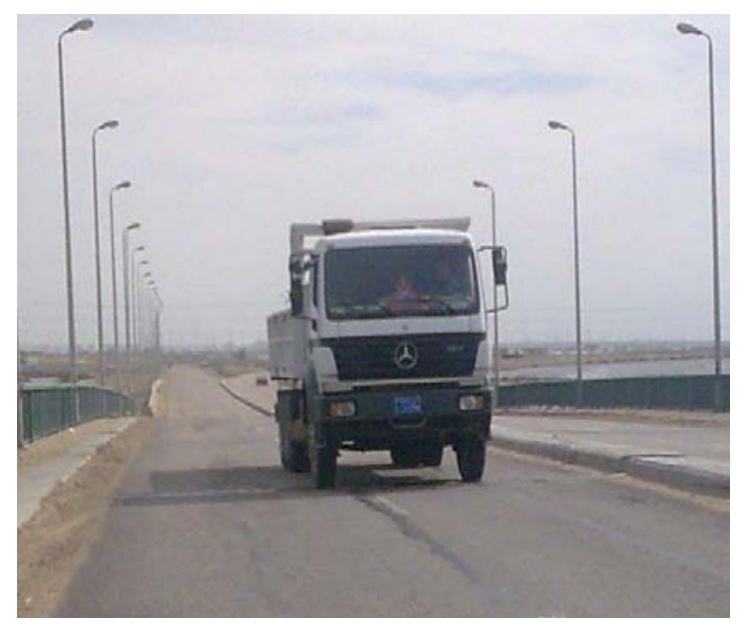

Fig. 9 The Vehicle Used During Test

\section{DATA ANALYSIS}

The collected data for tests No. 1, 2, and 3 were processed and filtered for each test. The tests descriptions are summarized in table (2).

Five records for each test were analyzed for each channel. The records are averaged and transformed to Power spectra curves and presented in the next figures.

Table (3) shows the comparison of the natural frequencies extracted from the three conducted tests.
Table 2, Tests Description

\begin{tabular}{|l|l|}
\hline Test No. & \multicolumn{1}{|c|}{ Description } \\
\hline Test 1 & Current Condition. \\
\hline Test 2 & After strengthening Works. \\
\hline Test 3 & After the special load was Passed. \\
\hline
\end{tabular}

Table 3, Comparison between the Natural Frequencies of the 3 Tests

\begin{tabular}{|c|c|c|c|c|}
\hline \multirow{2}{*}{$\begin{array}{c}\text { Mode } \\
\text { No. }\end{array}$} & \multicolumn{3}{|c|}{ Frequencies (Hz) } & \multirow{2}{*}{ Mode shape } \\
\cline { 2 - 4 } & Test 1 & Test 2 & Test 3 & \\
\hline \hline 01 & 4.04 & 4.79 & 4.80 & 1st Bending \\
\hline 02 & 5.16 & 5.30 & 5.30 & 1st Torsion \\
\hline
\end{tabular}

Studying the dynamic results shown in Table 3 for the three tests knowing that the flexural stiffness is the major parameter affected the dynamic bending mode, it can be noticed that the first test has the minimum natural frequency for the $1^{\text {st }}$ bending and $1^{\text {st }}$ torsion modes as expected (test 1 was performed before bridge strengthening).

Test no. 2 was performed after strengthening works to increase the bridge flexural stiffness were done and this was detected by the test.

The value of the changes in test results between test No.1 and test No. 2 were about 20\% increasing in the $1^{\text {st }}$ bending mode frequency and $3 \%$ increasing in the $1^{\text {st }}$ torsional mode frequency.

The results of test No. 2 are matched with calculations where the designed increase in the main girders flexural stiffness was $29 \%$.

The bridge torsion stiffness was slightly affected with increasing the flexural stiffness which is normally.

The tests results indicated that the executed strengthening works were effective.

Finally test no.3 was performed after the specific loads were passed, the measured natural frequencies shows almost no changes in the value of natural frequencies for $1^{\text {st }}$ bending mode and the $1^{\text {st }}$ torsional when comparing the results with test No. 2 .

These results indicated that the bridge load capacity was improved and the bridge did not affected by the specific load. 
Ahmed S. Hashad, "Measuring Bridge Flexural Strength Using Controlled Traffic Dynamic Test"
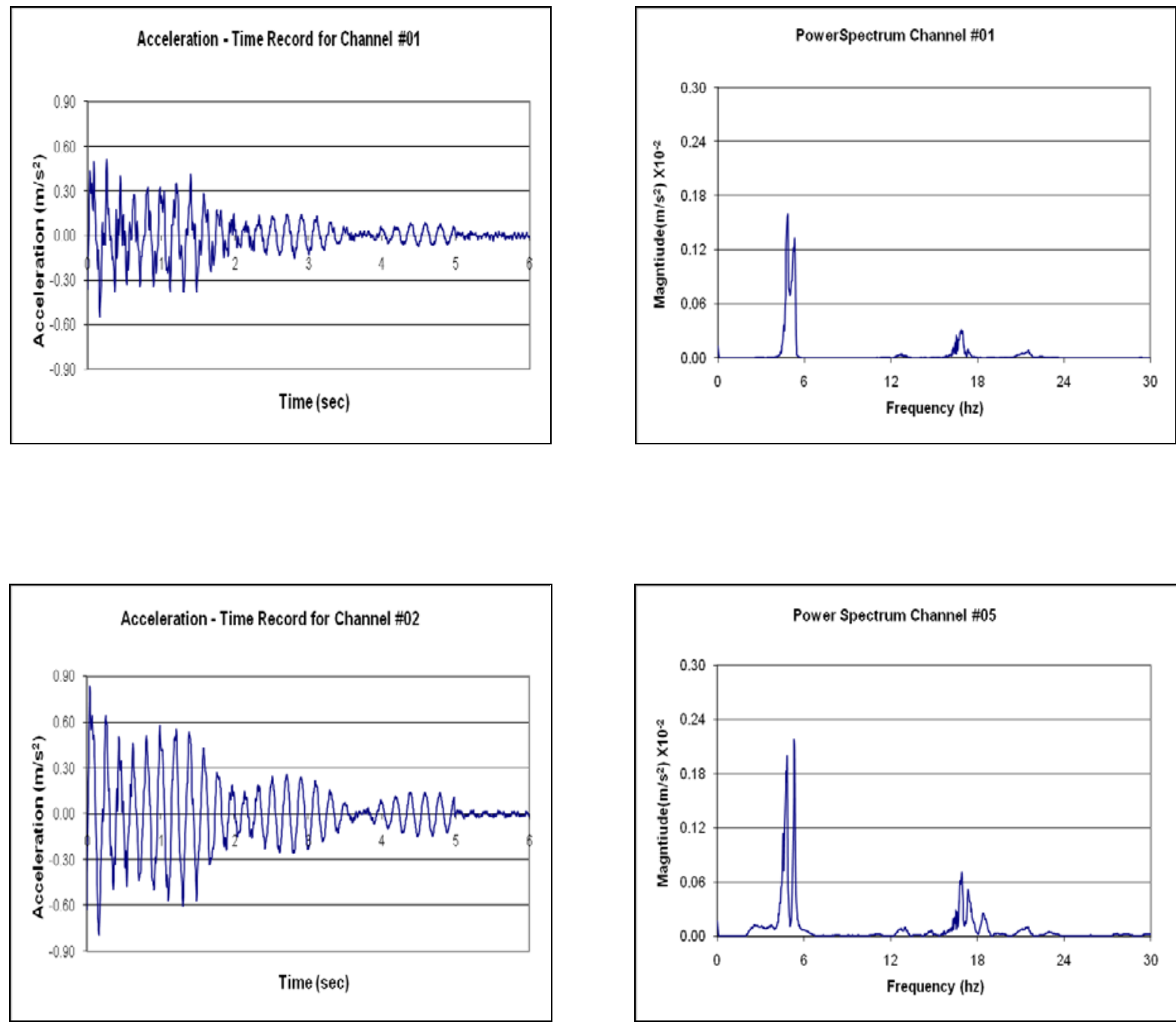

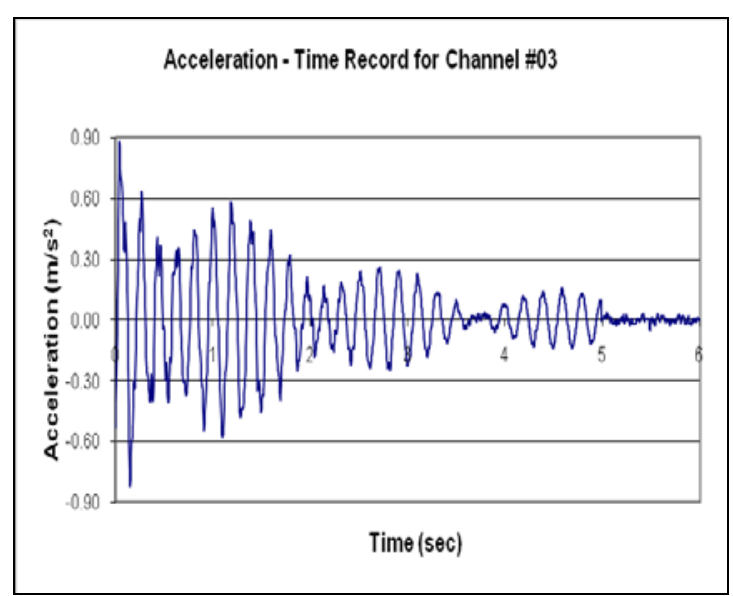

Fig. 10 Response Time- Test 02

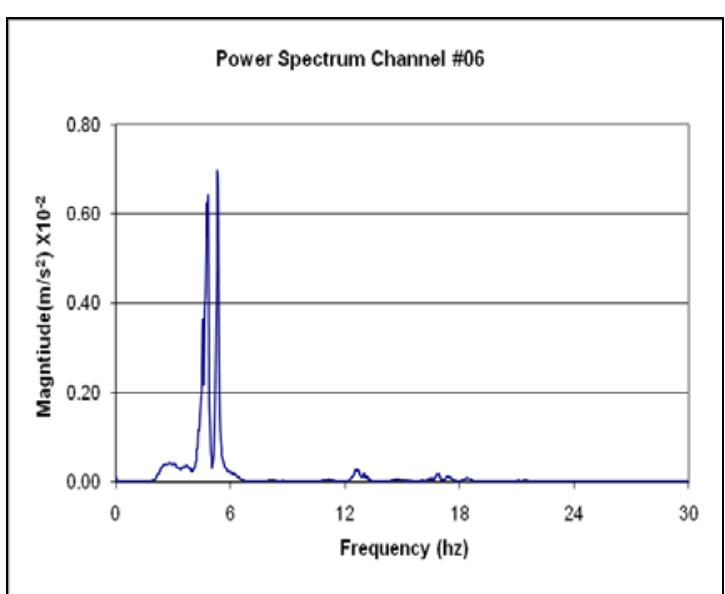

Fig. 11 Power Spectrum - Test 02 
Ahmed S. Hashad, "Measuring Bridge Flexural Strength Using Controlled Traffic Dynamic Test"
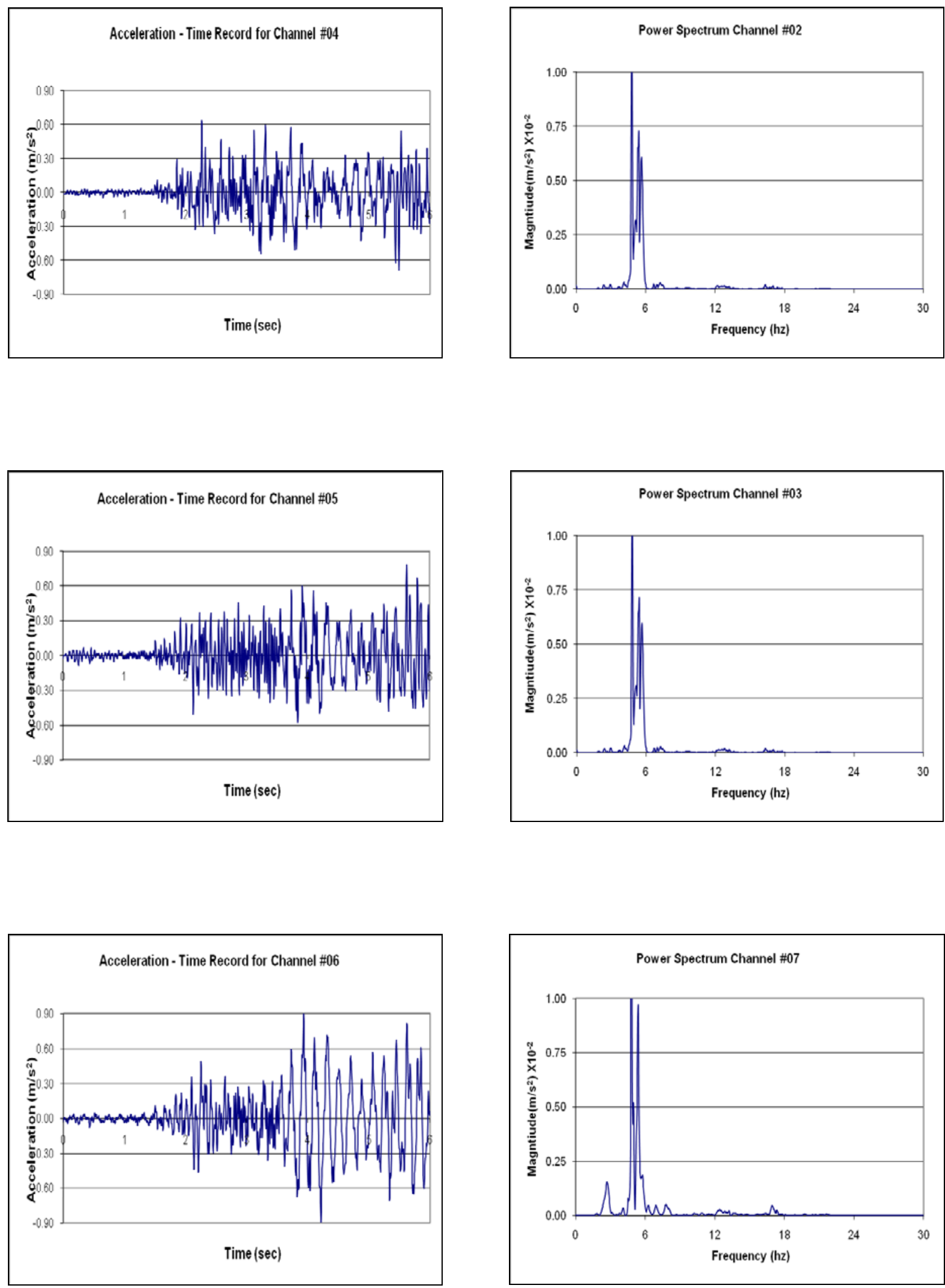

Fig. 12 Response Time Record - Test 03

Fig. 13 Power Spectrum - Test 03 


\section{CONCLUSIONS}

The increasing in the flexural stiffness of the bridge was determined using the increasing in the increasing in the $1^{\text {st }}$ bending mode frequency and the level of stress caused by the passing of the specific load was limited to elastic range. No damage happened as shown by test No. 3 .

\section{REFERENCES}

[1] Ewins, D.J., "Modal Testing Theory and Practice”, Engineering Dynamics Series, Research Studies Press LTD., Letchworth, Hertfordshire, England, 1985.

[2] Vibrant Technology Inc., "Me' Scope Software User Manual", USA, 2002

[3] M. Kamal, Yasser EL Hakem and A. Hashad "Assessment of Tawfikia Bridge Repair Works Using Modal Testing Technique” Proceedings of the $4^{\text {th }}$ International Conference on new Dimensions in Bridges, Flyover, Overpasses and Elevated Structures, October,2005, Fuzhou, China.
[4] Khalil, Wipf, Lowell and Russo. "Damage to Prestressed Concrete Bridges by over height Vehicles" 3rd World Conference on Structural Control, Como, Italy, Vol.3, 2002.

[5] Y. Robert, B. Raphael, O. Burdet and I. Smith. "Model Identification of Bridges Using Measurement Data" Computer-Aided Civil and Infrastructure Engineering 20, 2005. P.P 118131.

[6] Terry Wipf, M. Ritter and D. Wood. "Dynamic Evaluation And Testing of Timber Highway Bridges" Proceeding of Pacific Timber Engineering Conference, Newzealand, 1999, P.P.333-340.

[7] Samali, B., Li, JJ., Crews, K., and Al-Dawod, M., "Load Rating of Impaired Bridges Using Dynamic Method”, eJSE Journal, 2007, pp. 6675.

[8] M. Boore and Julian J. Bommer, "Processing of Strong - Motion Accelerograms : Needs, Options and Consequences" International Journal of Soil Dynamics and Earthquake Engineering, Vol.25,Feb. 2005, P.P. 93-115. 